\title{
Zagreb Radio Indices and Coindices
}

\author{
Anna Treesa Raj 1(D), Joseph Varghese Kureethara 2,*(D) \\ 1 Christ University, Department of Mathematics, Bangalore 560029, India; annatreesa.raj@ res.christuniversity.in (A.T.R.); \\ frjoseph@christuniversity.in (J.V.K.); \\ * Correspondence: frjoseph@christuniversity.in;
}

Scopus Author ID 57194694164

Received: 15.05.2021; Revised: 15.06.2021; Accepted: 18.06.2021; Published: 27.06.2021

\begin{abstract}
Zagreb radio index or coindex of a graph is defined based on the optimal radio labelling of the graph, where optimal refers to the labeling with a span equal to the radio number of the graph. We have defined the first and second Zagreb radio coindex, third Zagreb radio index, and coindex and calculated its value for some famous graphs. Furthermore, we established a certain relationship between Zagreb radio indices and the coindices of graphs.
\end{abstract}

Keywords: mathematical chemistry; topological index; Zagreb index; QSPR; QSAR.

(C) 2021 by the authors. This article is an open-access article distributed under the terms and conditions of the Creative Commons Attribution (CC BY) license (https://creativecommons.org/licenses/by/4.0/).

\section{Introduction}

Topological indices have already acquired a remarkable position in graph theory research. Its immense applications in the chemical field and its exciting mathematical computations attract the attention of numerous researchers. For the last few decades, there is a rapid increase in the study of topological indices. There are numerous results available in the literature.

Graph theory has an inevitable role in chemistry research since the structural formulas of covalently bonded compounds are graphs [1]. Topological indices are numerical values associated with such structural formulas. Initially, the information from topological indices was only used to obtain data regarding atom connectivity or molecular constitution. They could model different properties of saturated hydrocarbons that depended on molecular branchings, such as boiling point, molar refractivity, etc. Further researches have used topological indices to identify the nature of atoms and the bond multiplicity [5-23]. Its ability to model the biological activities of compounds made it useful in drug discovery. Moreover, it has pushed the research in topological indices research to higher levels [16]. Numerous topological indices have been proposed with respect to the degree of the vertices, eccentricity of the graph, chromatic number, etc. For many of them, its correlation between compounds' physicochemical or biological properties is yet to be found [7,17,20].

Zagreb indices are some of the oldest topological indices. They were introduced by Gutman and Trinajstić while studying the dependence of total $\pi$ - electron energy on molecular structure [8]. For a graph G, the first and second Zagreb indices are $M_{1}(G)=\sum_{u \in V(G)} d(v)^{2}$ and $M_{2}(G)=\sum_{u v \in E(G)} d(u) d(v)$, respectively, where $\mathrm{d}(\mathrm{v})$ is the degree of vertex $\mathrm{v}$ in $\mathrm{G}$ [25]. A new graph invariant called the third Zagreb index was introduced in 2011. It is defined as $M_{3}(G)=\sum_{u v \in E(G)}|d(u)-d(v)|[4]$. 
In 2008, Tomislav Došlić considered the contributions of nonadjacent pairs of vertices and proposed the idea of coindices. The first and second Zagreb coindices [3] are defined as, $\overline{M_{1}(G)}=\sum_{u v \notin E(G)} d(u)+d(v) \quad$ and $\overline{M_{2}(G)}=\sum_{u v \notin E(G)} d(u) d(v)$, respectively. The third Zagreb coindex was introduced in a similar way and is defined as $\overline{M_{3}(G)}=$ $\sum_{u v \notin E(G)}|d(u)-d(v)|[4]$.

In this paper, we define Zagreb radio indices and coindices and find some relations connecting them. These indices are analogous to the Zagreb indices, where the radiolabeling of the vertices replaces the degree of the vertices.

Radio-labeling of a graph $\mathbf{G}$ is a function $c$ from the vertex set of $\mathbf{G}$ to the set of natural numbers such that $|c(u)-c(v)| \geq \operatorname{diam}(G)+1-d(u, v)$, where $\operatorname{diam}(G)$ is the diameter of the graph $\mathbf{G}$ and $\mathrm{d}(\mathrm{u}, \mathrm{v})$ is the distance between $u$ and $v$ [2]. The largest label used by $c$ is called the span of $c$, and the smallest span among all possible radio labelings $c$ is the radio number of the graph, denoted by $\mathrm{rn}(\mathrm{G})$.

\section{The Zagreb Radio Indices}

The First and second Zagreb radio indices are defined as follows.

Definition 2.1.

The First Zagreb Radio Index of a graph $\mathrm{G}, M_{R 1}(G)$, is defined as the infimum of the set

$$
\sum_{\mathrm{uv} \in \mathrm{E}(\mathrm{G})}(\mathrm{c}(\mathrm{u})+\mathrm{c}(\mathrm{v}))
$$

where $\mathrm{c}$ is the radiolabeling having a span equal to the radio number of the graph.

$$
\text { i.e., } M_{R 1}(G)=\inf \left\{\sum_{u v \in E(G)}(c(u)+c(v)) \text { where c-span }(G) \text { is } \operatorname{rn}(G) \text {. }\right\}
$$

\section{Definition 2.2.}

The Second Zagreb Radio Index of a graph $G, M_{R 2}(G)$, is defined as the infimum of the set

$$
\sum_{u v \in E(G)}(c(u) c(v))
$$

where $\mathrm{c}$ is the radiolabeling having span equal to the radio number of the graph.

$$
\text { i.e., } M_{R 2}(G)=\inf \left\{\sum_{u v \in E(G)}(c(u) c(v)) \text { where c-span }(G) \text { is } \operatorname{rn}(G) \text {. }\right\}
$$

Defenition 2.3.

The First Zagreb coindex of a graph $\mathrm{G}, \bar{M}_{R 1}(\mathrm{G})$, is defined as the infimum of the set

$$
\sum_{\mathrm{uv} \notin \mathrm{E}(\mathrm{G})}(\mathrm{c}(\mathrm{u})+\mathrm{c}(\mathrm{v}))
$$

where $\mathrm{c}$ is the radiolabeling having a span equal to the radio number of the graph.

$$
\text { i.e., } \bar{M}_{R 1}(\mathrm{G})=\inf \left\{\sum_{u v \notin E(G)}(\mathrm{c}(\mathrm{u})+\mathrm{c}(\mathrm{v})) \text { where c-span }(\mathrm{G}) \text { is } \operatorname{rn}(\mathrm{G}) \text {. }\right\}
$$


Defenition 2.4.

The Second Zagreb coindex of a graph $\mathrm{G}, \bar{M}_{R 2}(\mathrm{G})$, is defined as the infimum of the set

$$
\sum_{u v \notin E(G)}(\mathrm{c}(\mathrm{u}) \mathrm{c}(\mathrm{v}))
$$

where $\mathrm{c}$ is the radiolabeling having span equal to the radio number of the graph.

$$
\text { i.e., } \bar{M}_{R 2}(\mathrm{G})=\inf \left\{\sum_{u v \notin E(G)}(\mathrm{c}(\mathrm{u}) \mathrm{c}(\mathrm{v})) \text { where c-span }(\mathrm{G}) \text { is } \operatorname{rn}(\mathrm{G}) .\right\}
$$

We compute the first and the second Zagreb radio coindex of some standard graphs.

\section{Theorem 2.1.}

The first Zagreb radio coindices of the star graphs, complete bipartite graphs, wheels graphs and gear graphs are

i. $\quad \bar{M}_{R 1}\left(S_{n}\right)=\frac{n^{3}-3 n^{2}+2 n}{2}$

ii. $\quad \bar{M}_{R 1}\left(K_{m, n}\right)=\frac{2 n^{3}+(4 m+4) n^{2}-4(4 m+6) n+\left(2 m^{3}-2 m\right)}{4}$

iii. $\left.\quad \bar{M}_{R 1}\left(W_{n}\right)=\frac{n^{3}-2 n^{2}-3 n}{2}\right)(\mathrm{n} \geq 5)$

iv. $\left.\quad \bar{M}_{R 1}\left(G_{n}\right)=\frac{32 n^{3}-11 n^{2}-73 n+42}{2}\right)(\mathrm{n} \geq 7)$

Proof. The first Zagreb radio coindex is the infimum of the set $\sum_{u v \notin E(G)}(c(u)+c(v))$ where $\mathrm{c}$ is the radiolabeling having a span equal to the radio number of the graph. Hence to prove the theorem, we need to find the labeling that leads to the required infimum.

\section{i. Star Graphs $\left(\mathbf{S}_{\mathbf{n}}\right)$}

Consider the star graph $S_{n}$ on n vertices. Label the peripheral vertices from 1 to (n-1) and the central vertex with $\operatorname{rn}\left(S_{n}\right)=\mathrm{n}+1$. Clearly, this is a radiolabeling of $S_{n}$ with span= $\operatorname{rn}\left(S_{n}\right)$

Consider $\sum_{u v \notin E\left(S_{n}\right)}(\mathrm{c}(\mathrm{u})+\mathrm{c}(\mathrm{v}))$

To find the sum, it is enough to add the label of each vertex, v, (n-1-d(v)) times.

Hence, $\sum_{u v \notin E\left(S_{n}\right)}(\mathrm{c}(\mathrm{u})+\mathrm{c}(\mathrm{v}))=\frac{n^{3}-3 n^{2}+2 n}{2}$

By the definition of the first Zagreb radio coindex $\bar{M}_{R 1}\left(S_{n}\right) \leq \frac{n^{3}-3 n^{2}+2 n}{2}$.

If $\bar{M}_{R 1}\left(S_{n}\right)<\frac{n^{3}-3 n^{2}+2 n}{2}$, then there should be another labeling $\mathrm{c} \neq \mathrm{c}$ such that the sum from c' is strictly less than the sum from c. Since we consider all the labels with a span equal to the radio number of the graph and $\mathrm{c} \neq \mathrm{c}$ assigns 1 to the central vertex and the peripheral vertices receive a label from 3 to $n+1$. But this sum is strictly greater than the sum by $\mathrm{c}$ since $\mathrm{n}$ and $n+1$ are contributing to the sum instead of 1 and 2 . Hence,

\section{ii. Complete Bipartite Graphs $\left(K_{m, n}\right)$}

$$
\bar{M}_{R 1}\left(S_{n}\right)=\frac{n^{3}-3 n^{2}+2 n}{2}
$$

Let $\mathrm{X}$ and $\mathrm{Y}$ be the partite sets of the complete bipartite graph $K_{m, n}$ with $|\mathrm{X}|=\mathrm{m} \geq \mathrm{n}=$ $|\mathrm{Y}|$

Consider the labeling $\mathrm{c}$. The vertices in $\mathrm{X}$ receive labels from 1 to $\mathrm{m}$ and the vertices in the second partite set, $\mathrm{Y}$, receive labels from $\mathrm{m}+2$ to $\mathrm{m}+\mathrm{n}+1$. But the radio number of $K_{m, n}$ is 
$m+n+1$. The vertices in the same partite set receives consecutive labellings since $d(u, v)=$ $\operatorname{diam}\left(K_{m, n}\right)$ where $\mathrm{u}, \mathrm{v} \in \mathrm{X}$ or $\mathrm{u}, \mathrm{v} \in \mathrm{Y}$. According to the definition of first Zagreb radio coindex label of each vertex, $v$ should be added $(m+n-1-d(v))$ times. Since this is a radiolabelling of $K_{m, n}$ with $\operatorname{span}=\operatorname{rn}\left(K_{m, n}\right)$,

$$
\bar{M}_{R 1}\left(K_{m, n}\right) \leq \frac{2 n^{3}+(4 m+4) n^{2}-4(4 m+6) n+\left(2 m^{3}-2 m\right)}{4}
$$

Assume if possible $\bar{M}_{R 1}\left(K_{m, n}\right)<\frac{2 n^{3}+(4 m+4) n^{2}-4(4 m+6) n+\left(2 m^{3}-2 m\right)}{4}$. Then there exist another labeling $\mathrm{c}^{\prime} \neq \mathrm{c}$ having span $=\operatorname{rn}\left(K_{m, n}\right)$ and $\sum_{u v \notin E\left(K_{m, n}\right)} \mathrm{c}^{\prime}(\mathrm{u}) \mathrm{c}^{\prime}(\mathrm{v})<$ $\sum_{u v \notin E\left(K_{m, n}\right)} \mathrm{c}(\mathrm{u}) \mathrm{c}(\mathrm{v})$. Since $\mathrm{c}^{\prime}$ has a span equal to the radio number, it cannot assign labels alternatively to vertices in $\mathrm{X}$ and $\mathrm{Y}$. Also, since $\mathrm{c}^{\prime} \neq \mathrm{c}, \mathrm{c}^{\prime}$ will be assigning labels 1 to $\mathrm{n}$ in $\mathrm{Y}$ and $\mathrm{n}+2$ to $\mathrm{n}+\mathrm{m}+1$ in $\mathrm{X}$. But $\sum_{u v \notin E\left(K_{m, n}\right)} \mathrm{c}^{\prime}(\mathrm{u}) \mathrm{c}^{\prime}(\mathrm{v})>\sum_{u v \notin E\left(K_{m, n}\right)} \mathrm{c}(\mathrm{u}) \mathrm{c}(\mathrm{v})$ since $\mathrm{m}+1$ is contributing to the sum instead of $n+1$ and $m>n$. Hence,

\section{iii. Wheel Graphs $\left(\mathbf{W}_{\mathbf{n}}\right)$}

$$
\bar{M}_{R 1}\left(K_{m, n}\right)=\frac{2 n^{3}+(4 m+4) n^{2}-4(4 m+6) n+\left(2 m^{3}-2 m\right)}{4}
$$

Let the wheel graph $W_{n}$ be on $n+1$ vertices and $n \geq 5$. Label the peripheral vertices with labels 1 to $n$ alternatively. The central vertex receives the label $n+2$, which is the radio number of the graph. According to the definition of the first Zagreb radio coindex, the order of the labels on the cycle will not affect the optimality of the sum, and the central vertex having the maximum label will not contribute to the sum. Hence this labeling gives the required infimum. Every vertex of $W_{n}$ on the cycle has (n-3) nonadjacent vertices. Therefore first Zagreb radio coindex of $W_{n}$ is the sum of (n-3) times each label of the vertices on the cycle. Hence,

$$
\left.\bar{M}_{R 1}\left(W_{n}\right)=\frac{n^{3}-2 n^{2}-3 n}{2}\right)
$$

\section{iv. Gear Graphs $\left(\mathbf{G}_{\mathbf{n}}\right)$}

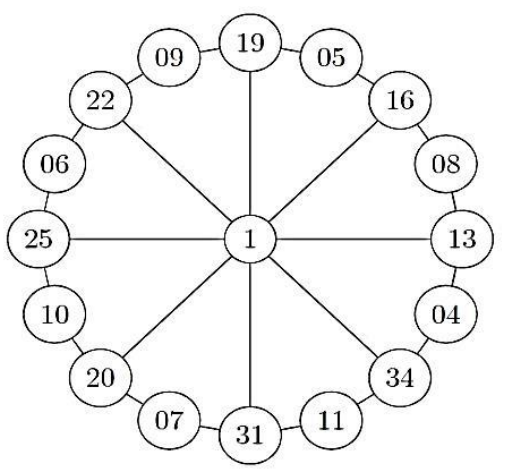

Figure 1: Optimum labelling for $G_{8}$

Consider the gear graph $G_{n}$ ) on $2 \mathrm{n}+1$ vertices and $\mathrm{n} \geq 7$. Let us consider the following labeling. Label the central vertex, $\mathrm{u}$, with 1 and the peripheral vertices, $v_{1}, v, \ldots, v_{n}$, with labels 4 to $(\mathrm{n}+3)$ alternatively. The vertex $w_{1}$ such that $\mathrm{d}\left(v_{n}, w_{1}\right)=3$ receives the label $\mathrm{n}+5$. Rest of the vertices, $w_{1}, w_{2}, \ldots, w_{n}$, get the labels $\mathrm{n}+8, \mathrm{n}+11, \ldots, 4 \mathrm{n}+2$. First, let us prove that this is a radiolabeling. Clearly $\left|\mathrm{c}(\mathrm{u})-\mathrm{c}\left(v_{i}\right)\right| \geq 5-\mathrm{d}\left(\mathrm{u}, v_{i}\right)=3$. Consider $\left|\mathrm{c}(\mathrm{u})-\mathrm{c}\left(w_{i}\right)\right| \geq|(\mathrm{n}+5)-1|=\mathrm{n}+4>$ $5-\mathrm{d}\left(\mathrm{u}, w_{i}\right)=4$. Since $v_{i} \mathrm{~s}$ are peripheral vertices, and every alternate vertex is at diametric distance; they are receiving consecutive labels. Now consider $v_{i}$ and $w_{i},\left|\mathrm{c}\left(v_{i}\right)-\mathrm{c}\left(w_{i}\right)\right| \geq \mid(\mathrm{n}+5)$ $(\mathrm{n}+3) \mid=2$. Clearly for each $v_{i}$ there exist a $w_{i}$ at a distance 3 . Hence this satisfies the condition for radiolabelling. Now for $w_{i}$, the distance between $w_{i}$ and $w_{j}$ is $2 \boldsymbol{V}_{i j}$ and label difference is 
greater than or equal to 3 . Hence the above labeling is radiolabelling. Now let us prove that this is the optimum labeling. The central vertex and each of the peripheral vertices have $n$ nonadjacent vertices. So the label of those vertices will be added $n$ times, and the label of the rest of the vertices will be added (n-1) times since they have (n-1) nonadjacent vertices. To optimize the sum, the vertices having n nonadjacent vertices should get the minimum possible labels. Hence,

$$
\left.\bar{M}_{R 1}\left(G_{n}\right)=\frac{32 n^{3}-11 n^{2}-73 n+42}{2}\right)
$$

Corollary 2.1.

Let $S_{n}$ be a star graph on n vertices and $G K_{n-1}$ be a complete graph on n-1 vertices, then

$$
\bar{M}_{R 1}\left(S_{n}\right)=\bar{M}_{R 1}\left(K_{n-1}\right) .
$$

\section{Theorem 2.2.}

The second Zagreb radio coindices of the star graphs and the complete bipartite graphs are:

i. $\quad \bar{M}_{R 2}\left(S_{n}\right)=\frac{3 n^{4}-10 n^{3}+9 n^{2}-2 n}{24}$

ii. $\quad \bar{M}_{R 2}\left(K_{m n}\right)=\frac{3 n^{4}+(12 m+14) n^{3}+\left(12 m^{2}+24 m+9\right) n^{2}-\left(12 m^{2}+36 m+26\right) n+\left(3 m^{4}+2 m^{3}-3 m^{2}-2 m\right)}{24}$

Proof

\section{i. Star Graphs $\left(\mathbf{S}_{\mathbf{n}}\right)$}

For star graph $S_{n}$, consider the labeling given in the proof of Theorem 2.1. This labeling gives the required infimum since the central vertex will not contribute to the sum. Referring to the definition of the second Zagreb radio coindex, the label of each vertex should be multiplied by the label of vertices that are not adjacent to it.

$$
\begin{aligned}
\bar{M}_{R 2}\left(S_{n}\right) & =\sum_{i=1}^{n-2} i\left(\frac{n(n-1)}{2}-\frac{i(i+1)}{2}\right) \\
= & \frac{3 n^{4}-10 n^{3}+9 n^{2}-2 n}{24}
\end{aligned}
$$

\section{ii. Complete Bipartite Graphs $\left(K_{m, n}\right)$}

The labeling mentioned in the proof of Theorem 2.1 helps us get the required infimum for a complete bipartite graph since $m \geq n$ and the label of each vertex are multiplied with the labels of the rest of the vertices in the partition set.

$$
\begin{aligned}
\bar{M}_{R 2}\left(K_{m n}\right)= & 1(2+3+\ldots+3)+2(3+4+\ldots+\mathrm{m})+\ldots+(\mathrm{m}-1) \mathrm{m}+(\mathrm{m}+2)(\mathrm{m}+3+\mathrm{m}+4+\ldots+\mathrm{m}+\mathrm{n}+1)+ \\
& (\mathrm{m}+3)(\mathrm{m}+4+\mathrm{m}+5+\ldots+\mathrm{m}+\mathrm{n}+1)+\ldots+(\mathrm{m}+\mathrm{n})(\mathrm{m}+\mathrm{n}+1) \\
= & \sum_{i=1}^{m-1} i\left(\frac{m(m+1)}{2}-\frac{i(i+1)}{2}+\sum_{i=m+2}^{m+n} i\left(\frac{(m+n+2)(m+n+1)}{2}-\frac{i(i+1)}{2}\right.\right. \\
= & \frac{3 n^{4}+(12 m+14) n^{3}+\left(12 m^{2}+24 m+9\right) n^{2}-\left(12 m^{2}+36 m+26\right) n+\left(3 m^{4}+2 m^{3}-3 m^{2}-2 m\right)}{24}
\end{aligned}
$$

Corollary 2.2.

Let $S_{n}$ be a star graph on $\mathrm{n}$ vertices and $K_{n-1}$ be a complete graph on n-1 vertices, then

$$
\bar{M}_{R 2}\left(S_{n}\right)=\bar{M}_{R 2}\left(K_{n-1}\right.
$$




\section{The Third Zagreb Radio Index and Coindex}

\section{Definition 3.1.}

The third Zagreb Radio Index of a graph $\mathrm{G}, \boldsymbol{M}_{\boldsymbol{R} 3}(\boldsymbol{G})$, is defined as the infimum of the set $\sum_{\boldsymbol{u} \boldsymbol{v} \in \boldsymbol{E}(\boldsymbol{G})}|\boldsymbol{c}(\boldsymbol{u})-\boldsymbol{c}(\boldsymbol{v})|$, where $c$ is the radiolabeling having span equal to the radio number of the graph.

$$
\text { i. e. , } M_{R 3}(G)=\inf \left\{\sum_{u v \in E(G)}|c(u)-c(v)| \text { where } c-\operatorname{span} \text { is } \operatorname{rn}(G) \text {. }\right\}
$$

\section{Definition 3.2.}

The third Zagreb Radio Coindex of a graph $G, \overline{\boldsymbol{M}_{-} \boldsymbol{R} \mathbf{3}}(\boldsymbol{G})$, is defined as the infimum of the set $\sum_{\boldsymbol{u} \boldsymbol{v} \notin \boldsymbol{E}(\boldsymbol{G})}|\boldsymbol{c}(\boldsymbol{u})-\boldsymbol{c}(\boldsymbol{v})|$, where $c$ is the radiolabeling having span equal to the radio number of the graph.

$$
\text { i.e., } \overline{M_{-} R 3}(G)=\inf \left\{\sum_{u v \notin E(G)}|c(u)-c(v)| \text { where } c-\operatorname{span} \text { is } \operatorname{rn}(G) \text {. }\right\}
$$

We compute the third Zagreb index of some standard graphs.

\section{Theorem 3.1.}

The third Zagreb radio indices of the complete graphs, star graphs, complete bipartite graphs and wheel graphs are:

i. $\quad M_{R 3}\left(K_{n}\right)=\frac{n^{3}-n}{6}$

ii. $\quad M_{R 3}\left(S_{n}\right)=\frac{n^{2}+n-2}{2}$

iii. $\quad M_{R 3}\left(K_{m, n}\right)=\frac{m n^{2}+\left(m^{2}+2 m\right) n}{2}$

iv. $\quad M_{R 3}\left(W_{n}\right)=\frac{n^{2}+11 n-16}{2}$

Proof.

\section{i. Complete Graphs $\left(\mathbf{K}_{\mathbf{n}}\right)$}

Since the diameter of a complete graph is 1, by the definition of radiolabelling, complete graphs admit consecutive radiolabeling. Hence,

$$
\begin{aligned}
& M_{R 3}\left(K_{n}\right)=|\mathbf{1}-2|+|\mathbf{1}-\mathbf{3}|+\cdots+|\mathbf{1}-\mathbf{n}|+|\mathbf{2}-\mathbf{3}| \\
+ & |2-\quad \mathbf{4}|+\cdots+|\mathbf{2}-\mathbf{n}|+\cdots+|(\mathbf{n}-\mathbf{1})-\mathbf{n}| \\
= & (\mathbf{2}-\mathbf{1})+(\mathbf{3}-\mathbf{1})+\cdots+(\mathbf{n}-\mathbf{1})+(\mathbf{3}-\mathbf{2})+(\mathbf{4}-\mathbf{2})+\cdots+(\mathbf{n}-\mathbf{2}) \\
& +\cdots+(\mathbf{n}-(\mathbf{n}-\mathbf{1}))
\end{aligned}
$$




$$
=\sum_{i=1}^{n-1} i(i+1)+\sum_{i=1}^{n-1}-i(n-i)=\frac{n^{3}-n}{6}
$$

\section{ii. Star Graphs $\left(\mathbf{S}_{\mathbf{n}}\right)$}

Let us consider the star graph $\boldsymbol{S}_{\boldsymbol{n}}$ on n vertices. Any labeling with a span equal to the radio number leads to the same result as we are considering the sum of the difference of the labels of the adjacent vertices. Let us consider the labeling where the central vertex receives 1 , and the rest of the vertices get labels from 3 to $n+1$. The label differences will be $2,3, \ldots, n$. Hence,

$$
M_{R 3}\left(S_{n}\right)=\frac{n^{2}+n-2}{2}
$$

\section{iii. Complete Bipartite Graphs $\left(K_{m, n}\right)$}

As mentioned above, any labeling with span equals the radio number of the complete bipartite graph $\boldsymbol{K}_{\boldsymbol{m}, \boldsymbol{n}}$ leads to the same result as we are considering the sum of the difference of the labels of the adjacent vertices. Let us consider that the labeling starts with the partite set having more vertices. By definition, $\mathrm{n}$ times the sum of the labels of the partite set having more vertices added to $m$ times the sum of the labels of the second partite set leads to the required result. Hence,

$$
M_{R 3}\left(K_{m, n}\right)=\frac{m n^{2}+\left(m^{2}+2 m\right) n}{2}
$$

\section{iv. Wheel Graphs $\left(\mathbf{W}_{\mathbf{n}}\right)$}

Consider the wheel graph $\boldsymbol{W}_{\boldsymbol{n}}$ on $\mathrm{n}+1$ vertices. Since adjacent vertices cannot have consecutive labels, let us arrange the labels at a difference 2 as follows.

\section{When $n$ is odd}

Label the vertices on the cycle with numbers $1,3,5, \ldots, \mathrm{n}$ and $2,4,6, \ldots, \mathrm{n}-1$ continuously. The difference between the labels of the adjacent vertices will be 2 except the label $n-1$ will be adjacent to label 1 and $n$ will be adjacent to 2 . The central vertex, adjacent to all the vertices on the cycle, receives the label $n+2$.

$$
\begin{aligned}
& \text { Therefore, } \boldsymbol{M}_{\boldsymbol{R} 3}\left(\boldsymbol{W}_{n}\right)=\frac{2(n-1)}{2}+\frac{2(n-3)}{2}++(\mathrm{n}-1-1)+(\mathrm{n}-2)+(\mathrm{n}+2-1)+(\mathrm{n}+2- \\
& 2)+\ldots+(\mathrm{n}+2-\mathrm{n})=\frac{n^{2}+11 n-16}{2}
\end{aligned}
$$

\section{When $\mathbf{n}$ is even}

Label the vertices on the cycle with numbers $1,3,5, \ldots, \mathrm{n}-1$ and $2,4,6, \ldots, \mathrm{n}$ continuously. The difference between the labels of the adjacent vertices will be 2 except the label $n$ will be adjacent to label 1 and n-1 will be adjacent to 2 . The central vertex, adjacent to all the vertices on the cycle, receives the label $n+2$. 
Therefore, $\boldsymbol{M}_{\boldsymbol{R} 3}\left(\boldsymbol{W}_{n}\right)=\frac{2(n-1)}{2}+\frac{2(n-3)}{2}++(\mathrm{n}-1-2)+(\mathrm{n}-1)+(\mathrm{n}+2-1)+(\mathrm{n}+2-$

$2)+\ldots+(\mathrm{n}+2-\mathrm{n})=\frac{n^{2}+11 n-16}{2}$

\section{Theorem 3.2.}

The third Zagreb radio coindices of the star graphs, complete bipartite graphs, and wheel graphs are:

$$
\begin{array}{ll}
\text { i. } & \overline{M_{R 3}\left(S_{n}\right)}=\frac{n^{3}}{6}-\frac{n^{2}}{2}+\frac{n}{3} \\
\text { ii. } & \overline{M_{R 3}\left(K_{m, n}\right)}=\frac{n^{3}-n+m^{3}-m}{6} \\
\text { iii. } & \overline{M_{R 3}\left(W_{n}\right)}=\left\{\begin{array}{l}
\frac{4 k^{3}}{3}-2 k^{2}-\frac{k}{3} \text { if } n=2 k \\
\frac{4 k^{3}}{3}-\frac{4 k}{3} \text { if } n=2 k+1
\end{array}\right.
\end{array}
$$

Proof.

\section{i. Star Graphs $\left(\mathbf{S}_{\mathbf{n}}\right)$}

Since the labels on the peripheral vertices are consecutive, any labeling with a span equal to the radio number leads to the same result. Let us consider the labeling where the peripheral vertices receive labels from 1 to $n-1$. By defining the third Zagreb radio coindex, we have to consider the difference between the labels of each pair of peripheral vertices.

$$
\text { i.e } \begin{aligned}
\overline{M_{R 3}\left(S_{n}\right)} & =\sum_{i=1}^{n-2} i(i+1)+\sum_{i=1}^{n-2}-i(n-(i+1)) \\
& =\frac{n^{3}}{6}-\frac{n^{2}}{2}+\frac{n}{3}
\end{aligned}
$$

\section{ii. Complete Bipartite Graphs $\left(K_{m, n}\right)$}

Now consider the complete bipartite graph $\boldsymbol{K}_{\boldsymbol{m}, \boldsymbol{n}}$ on $\mathrm{m}+\mathrm{n}$ vertices. Since the labels of the vertices in each partite set are consecutive, any labeling with a span equals the radio number leads to the same result. Let us consider that the labeling starts with the partite set having more vertices. By the definition of the third Zagreb radio coindex, the sum of the differences in the vertices' labels in the respective partite sets leads to the required result.

$$
\begin{aligned}
& \text { Therefore, } \overline{M_{R 3}\left(K_{m, n}\right)}=\sum_{i=1}^{m-1} i(i+)+\sum_{i=1}^{m-1}-i(m-i)+ \\
& \begin{array}{c}
\sum_{i=1}^{n-1} i(m+i+2)+\sum_{i=1}^{n-1}-(m+i+1)(n-i) \\
=\frac{n^{3}-n+m^{3}-m}{6}
\end{array}
\end{aligned}
$$




\section{iii. Wheel Graphs $\left(\mathbf{W}_{\mathbf{n}}\right)$}

In the case of the wheel graph $\boldsymbol{W}_{\boldsymbol{n}}$, to minimize the sum, labels with a higher difference should be adjacent. The central vertex should get the maximum label as it will not contribute to the sum. Consider the following labeling.

\section{Case 1: $\mathbf{n}=\mathbf{2 k}$}

\section{Subcase 1: $k$ is even}

Choose any vertex on the cycle and label the vertex as 1 . The numbers having maximum difference with 1 are $n$ and $n-1$. Hence, label the vertices adjacent to 1 with $n$ and $n-1$.

The labels having maximum difference with $n$ and $n-1$ are 2 and 3. Since $(n-2)+((n-1)-$ $3)=(n-3)+((n-1)-2), 2$ or 3 can be adjacent to any of $n$ and $n-1$. Let 2 be adjacent to $n$, and 3 be adjacent to $\mathrm{n}-1$. Continuing like this, the last 3 vertices will end up with labels $\mathrm{k}+1, \mathrm{k}$, and $\mathrm{k}+2$. Since $k$ and $k+2$ cannot be adjacent to $k+1$, swap the labels $k-2$ and $k$, resulting in the required labeling. From the labeling, the labels 1 to $\mathrm{k}$ are adjacent to numbers with greater magnitude, and the rest are adjacent to numbers with a magnitude less than them. Hence,

$$
\begin{aligned}
\overline{M_{R 3}\left(W_{n}\right)}= & \sum_{i=1}^{k}-i(n-3-(i-1)) \\
& +\sum_{i=1}^{k-1} i(i+1) \\
& +\sum_{i=1}^{k-1}-(k+i)(n-3-(k+(i-3))) \\
& +\sum_{i=1}^{k}(k+i-3)(k+i) \\
& =\frac{4 k^{3}}{3}-2 k^{2}-\frac{k}{3}
\end{aligned}
$$

\section{Subcase 2: $k$ is odd}

Label as in Subcase 1. The last three will end up with labels k-1, k+1, and k. Since k1 and $k+1$ cannot be adjacent to $k$, swap the labels $k+1$ and $k+3$. Computation leads to the same result as in Subcase 1.

\section{Case 2: $n=2 k+1$}

Labeling like in Case 1, we will end up with labels $k+1$ and $k+2$ together. Swap the labels $\mathrm{k}+1$ and $\mathrm{k}-1$. In this case, labels from 1 to $\mathrm{k}$ are adjacent to numbers having greater magnitude, $\mathrm{k}+1$ is adjacent to a number having greater magnitude, and another has a magnitude less than that, and the numbers $\mathrm{k}+2$ to $\mathrm{n}$ are attached to numbers having a magnitude less than them. Thus, 


$$
\begin{aligned}
\overline{M_{R 3}\left(W_{n}\right)}= & \sum_{i=1}^{k}-i(n-3-(i-1)) \\
& +\sum_{i=1}^{k-1} i(i+1)+(k-1)(k+1)-(k+1)(n-k-2) \\
& +\sum_{i=1}^{k-1}-(k+(i+1))(n-3-(k+(i+1)-3)) \\
& +\sum_{i=1}^{k}(k+(i+1)-3)(k+i+1)=\frac{4 k^{3}}{3}-\frac{4 k}{3}
\end{aligned}
$$

\section{Relations for Zagreb Radio Indices and Coindices}

If $\mathrm{G}$ is a self-complementary graph, then

$$
\left.M_{R 1}(\bar{G})=\bar{M}_{R 1}(G)=\bar{M}_{R 1} \bar{G}\right) \text {. }
$$

Theorem 4.1.

Let $\mathrm{G}$ be a graph with $\mathrm{n}$ vertices such that $\mathrm{r}<\mathrm{r}^{\prime}$, where $\mathrm{r}$ and $\mathrm{r}^{\prime}$ are the radio numbers of $\mathrm{G}$ and $\bar{G}$ respectively. Then

$$
\begin{aligned}
& M_{R 1}(\bar{G})<(\mathrm{n}-1) \frac{\mathrm{r} \prime(\mathrm{r}+1)}{2}-M_{R 1}(G) \\
& \overline{M_{R 1}(G)} \leq(\mathrm{n}-1) \frac{\mathrm{r}(\mathrm{r}+1)}{2}-M_{R 1}(G) \\
& \overline{M_{R 1}(\bar{G})}>M_{R 1}(G)
\end{aligned}
$$

Proof. By the definition of the first Zagreb radio index

$$
\begin{aligned}
M_{R 1}(\bar{G}) & =\sum_{u v \in E(\bar{G})} \mathrm{c}^{\prime}(\mathrm{u})+\mathrm{c}^{\prime}(\mathrm{v}) \\
& =d^{\prime}{ }_{1} \mathrm{c}^{\prime}\left(v_{1}\right)+d_{2}^{\prime} \mathrm{c}^{\prime}\left(v_{2}\right)+\ldots+d^{\prime} \mathrm{c}^{\prime}\left(v_{\mathrm{n}}\right) \\
& =\left(\mathrm{n}-1-d_{1}\right) \mathrm{c}^{\prime}\left(v_{1}\right)+\left(\mathrm{n}-1-d_{2}\right) \mathrm{c}^{\prime}\left(v_{2}\right)+\ldots\left(\mathrm{n}-1-d_{\mathrm{n}}\right) \mathrm{c}^{\prime}\left(v_{\mathrm{n}}\right) \\
& =(\mathrm{n}-1)\left(\mathrm{c}^{\prime}\left(v_{1}\right)+\mathrm{c}^{\prime}\left(v_{2}\right) \ldots+\mathrm{c}^{\prime}\left(v_{\mathrm{n}}\right)\right)-\left(d_{1} \mathrm{c}^{\prime}\left(v_{1}\right)+d_{2} \mathrm{c}^{\prime}\left(v_{2}\right)+\ldots+d_{\mathrm{n}} \mathrm{c}^{\prime}\left(v_{\mathrm{n}}\right)\right) \\
& \leq(\mathrm{n}-1) \frac{\mathrm{r}\left(\mathrm{r}^{\prime}+1\right)}{2}-\left(d_{1} \mathrm{c}^{\prime}\left(v_{1}\right)+d_{2} \mathrm{c}^{\prime}\left(v_{2}\right)+\ldots+d_{\mathrm{n}} \mathrm{c}^{\prime}\left(v_{\mathrm{n}}\right)\right) \\
& <(\mathrm{n}-1) \frac{\mathrm{r}(\mathrm{r} \prime+1)}{2}-M_{R 1}(G)
\end{aligned}
$$

Inequality holds since $\mathrm{r}<\mathrm{r}^{\prime}, d_{\mathrm{i}}^{\prime}$ is the degree of $i^{\text {th }}$ vertex in $\bar{G}$ and $\mathrm{c}^{\prime}$ is the radiolabelling of $\bar{G}$. Hence (1) holds.

Again by the definition of the first Zagreb radio coindex,

$$
\begin{aligned}
\overline{M_{R 1}(\bar{G})} & =\sum_{u v \notin E(\mathrm{G})} \mathrm{c}(\mathrm{u})+\mathrm{c}(\mathrm{v}) \\
& =\sum_{u v \in E(\bar{G})} \mathrm{c}(\mathrm{u})+\mathrm{c}(\mathrm{v}) \\
& =d^{\prime}{ }_{1} \mathrm{c}\left(v_{1}\right)+d^{\prime}{ }_{2} \mathrm{c}\left(v_{2}\right)+\ldots+d^{\prime}{ }_{\mathrm{n}} \mathrm{c}\left(v_{\mathrm{n}}\right) \\
& =(\mathrm{n}-1)\left(\mathrm{c}\left(v_{1}\right)+\mathrm{c}\left(v_{2}\right) \ldots+\mathrm{c}\left(v_{\mathrm{n}}\right)\right)-\left(d_{1} \mathrm{c}\left(v_{1}\right)+d_{2} \mathrm{c}\left(v_{2}\right)+\ldots+d_{\mathrm{n}} \mathrm{c}\left(v_{\mathrm{n}}\right)\right) \\
& \leq(\mathrm{n}-1) \frac{\mathrm{r}(\mathrm{r}+1)}{2}-\left(d_{1} \mathrm{c}\left(v_{1}\right)+d_{2} \mathrm{c}\left(v_{2}\right)+\ldots+d_{\mathrm{n}} \mathrm{c}\left(v_{\mathrm{n}}\right)\right) \\
& =(\mathrm{n}-1) \frac{\mathrm{r}(\mathrm{r}+1)}{2}-M_{R 1}(G)
\end{aligned}
$$

Hence (2) holds. Result (3) is immediate from the definition since $r<r$. Hence the proof. 
Corollary 4.1.

Let $\mathrm{G}$ be a graph on $\mathrm{n}$ vertices. Then,

$M_{R 1}(\bar{G})=(\mathrm{n}-1) \frac{\mathrm{r} /(\mathrm{r} /+1)}{2}-M_{R 1}(G)$ if and only if $\mathrm{G}$ is a self-complementary graph admitting consecutive radiolabelling.

Corollary 4.1.

Let $\mathrm{G}$ be a graph on $\mathrm{n}$ vertices. Then,

$\overline{M_{R 1}(G)}=(\mathrm{n}-1) \frac{\mathrm{r}(\mathrm{r}+1)}{2}-M_{R 1}(G)$ if and only if $\mathrm{G}$ admits consecutive radio labelling.

Theorem 4.2.

Let $\mathrm{G}$ be a graph on $\mathrm{n}$ vertices with $\mathrm{r}<\mathrm{r}$, where $\mathrm{r}$ and $\mathrm{r}^{\prime}$ are the radio numbers of $\mathrm{G}$ and $\overline{\boldsymbol{G}}$ respectively. Then

$$
\begin{aligned}
& M_{R 2}(\bar{G})<M_{R 2}\left(K_{r^{\prime}}\right)-M_{R 2}(G) \\
& \overline{M_{R 2}(G)}<M_{R 2}\left(K_{r^{\prime}}\right)-M_{R 2} \\
& \overline{M_{R 2}(\bar{G})}>M_{R 2}(G)
\end{aligned}
$$

Proof.

Consider the graph $\mathrm{G}$ having vertices $\boldsymbol{v}_{\mathbf{1}}, \boldsymbol{v}_{\mathbf{2}}, \ldots, \boldsymbol{v}_{\boldsymbol{n}}$. Let $\mathrm{c}$ and c' be the optimum radio labelings of $\mathrm{G}$ and $\overline{\boldsymbol{G}}$ respectively. Then,

$$
\begin{gathered}
\sum_{i=1}^{n-1} \sum_{j=i+1}^{n} c^{\prime}\left(v_{i}\right) c^{\prime}\left(v_{j}\right)=\sum_{u v \in E(\bar{G})} c^{\prime}(u) c^{\prime}(v)+\sum_{u v \notin E(\bar{G})} c^{\prime}(u) c^{\prime}(v) \\
=\sum_{u v \in E(\bar{G})} c^{\prime}(u) c^{\prime}(v)+\sum_{u v \in E(G)} c^{\prime}(u) c^{\prime}(v) \\
=M_{R 2}(\bar{G})+\sum_{u v \in \mathrm{E}(\mathrm{G})} c^{\prime}(u) c^{\prime}(v) \\
>M_{R 2}(\bar{G})+M_{R 2}(G)
\end{gathered}
$$

(Since r'>r.) So,

$$
M_{R 2}(\bar{G})+M_{R 2}(G)<\sum_{i=1}^{n-1} \sum_{j=i+1}^{n} c^{\prime}\left(v_{i}\right) c^{\prime}\left(v_{j}\right) \leq M_{R 2}\left(K_{r^{\prime}}\right)
$$

where $\boldsymbol{K}_{\boldsymbol{r}}$, is the complete graph on r' vertices, and the inequality holds since it has the radio number $r$ ' and all vertices are adjacent to each other.

Therefore,

$$
M_{R 2}(\bar{G})<M_{R 2}\left(K_{r^{\prime}}\right)-M_{R 2}(G)
$$

Hence the result. To prove the next inequality, 


$$
\begin{gathered}
\overline{M_{R 2}(G)}=\sum_{u v \notin \mathrm{E}(\mathrm{G})} c(u) c(v) \\
=\sum_{u v \in E(\bar{G})} c(u) c(v) \\
<\sum_{u v \in E(\bar{G})} c^{\prime}(u) c^{\prime}(v) \\
=M_{R 2}(G)
\end{gathered}
$$

Now from (4) we get (5). Hence the result. (6) is immediate from the definition of second Zagreb radio coindex since $r^{\prime}>r$.

Theorem 4.3.

Let $\mathrm{G}$ be a graph of order $\mathrm{n}$ and size $\mathrm{m}$ and let $\mathrm{m}$ ' be the size of $\overline{\boldsymbol{G}}$. If $\mathrm{m} \geq \mathrm{m}$ ' then $M_{R 3}(G)>\overline{M_{R 3}(G)}$

\section{Proof.}

The result is true for $\boldsymbol{K}_{n}$ for all n since $\overline{\boldsymbol{M}_{R 3}}\left(\boldsymbol{K}_{n}\right)=\mathbf{0}$.

Without loss of generality, assume that $\boldsymbol{G} \neq \boldsymbol{K}_{\boldsymbol{n}}$.

By the definition of the third Zagreb radio index,

$$
\begin{aligned}
M_{R 3}(G) & =\sum_{u v \in E(G)}|c(u)-c(v)| \\
& =\sum_{i=1}^{m} a_{i}
\end{aligned}
$$

where $\boldsymbol{a}_{\boldsymbol{i}}$ is the label difference of the end vertices of the $i^{\text {th }}$ edge.

By the definition of radiolabelling $\boldsymbol{a}_{\boldsymbol{i}} \geq \operatorname{diam}(\mathrm{G})$.

Hence $M_{\boldsymbol{R} 3}(G) \geq \boldsymbol{m} \cdot \operatorname{diam}(\mathrm{G})$.

Also, by the definition of the third Zagreb radio coindex,

$$
\begin{aligned}
\overline{M_{-} R 3}(G) & =\sum_{u v \notin E(G)}|c(u)-c(v)| \\
& =\sum_{i=1}^{m \prime} a_{i}
\end{aligned}
$$

where $\boldsymbol{a}_{\boldsymbol{i}}$ is the label difference of the vertices which are not adjacent in G.

Since $\boldsymbol{G} \neq \boldsymbol{K}_{\boldsymbol{n}}$, there exist at least one $\boldsymbol{a}_{\boldsymbol{i}}$ such that $\left.\boldsymbol{a}_{\boldsymbol{i}}\right\}<\operatorname{diam}(\mathrm{G})$.

So by the assumption $\mathbf{m} \geq \mathbf{m}^{\prime}$ and from (10) $\boldsymbol{M}_{\boldsymbol{R} 3}(\boldsymbol{G})>\overline{\boldsymbol{M}_{\boldsymbol{R} 3}(\boldsymbol{G})}$.

\section{Conclusions}

Knowledge of the physio-chemical properties and biological properties of molecules and compounds is vital in many studies. In neural networks, vaccine research, drug research, and efficient and cost-effective methods are very much in need. In this context, the study of molecules and compounds from the structural perspective is of great significance. Ever since the introduction of topological indices, there is a huge sigh of relief. Researchers worldwide 
work collaboratively to find mathematically and using high power computing techniques the correlation between topological properties and the actual properties of molecules and compounds. We have introduced the Zagreb radio indices and the Zagreb radio coindices. We hope the results obtained in this paper bring the structural studies and experimental studies closer than ever.

\section{Funding}

This research received no external funding.

\section{Acknowledgments}

We would like to thank the editor-in-chief and the reviewers for their valuable suggestions.

\section{Conflicts of Interest}

The authors declare no conflict of interest

\section{References}

1. Balaban, T. Applications of graph theory in chemistry, J. Chem. Inf. Comput. Sci. 1985, 25, 334-343, https://doi.org/10.1021/ci00047a033.

2. Chartrand, G.; Erwin, D.; Harary, F.; Zhang, P. Radio labelings of graphs, Bull. Inst. Comb. Appl. 2001, 33 , 77-85.

3. Doslic, T. Vertex-weighted wiener polynomials for composite graphs, Ars Math. Contem. 2008, 1, 66-80, https://doi.org/10.26493/1855-3974.15.895

4. Fath-Tabar, G.H. Old and new Zagreb indices of graphs, MATCH Commun. Math. Comput. Chem. 2011, 65, 79-84.

5. Gao, W.; Iqbal, Z.; Ishaq, M.; Aslam, A.; Sarfraz, R. Topological aspects of dendrimers via distance based descriptors, IEEE Access 2019, 7, 35619-35630, https://doi.org/10.1109/ACCESS.2019.2904736.

6. Gao, W.; Younas, M.; Farooq, A.; Virk, A.; Nazeer, W. Some reverse degree-based topological indices and polynomials of dendrimers, Math. 2018, 6, 214, https://doi.org/10.3390/math6100214.

7. Gutman, I. Degree-based topological indices, Croat. Chem. Acta 2013, 86, 351-361, http://dx.doi.org/10.5562/cca2294.

8. Gutman, I.; Trinajstić, N. Graph theory and molecular orbitals. Total $\pi$-electron energy of alternant hydrocarbons, Chem. Phys. Lett. 1972, 17, 535-538, https://doi.org/10.1016/0009-2614(72)85099-1.

9. Imran, M.; Bokhary, S.; Manzoor, S.; Siddiqui, M.K. On molecular topological descriptors of certain families of nanostar dendrimers, Eurasian Chem. Commun. 2020, 2, 680-687, https://doi.org/10.33945/SAMI/ECC.2020.6.5.

10. Imran, M.; Siddiqui, M.; Ahmad, S.; Hanif, M.; Muhammad, M.H.; Farahani, M. Topological properties of benzenoid, phenylenes and nanostar dendrimers, J. Discrete Math. Sci. Cryptogr. 2019, 22, 1229-1248, https://doi.org/10.1080/09720529.2019.1701267

11. Iqbal, Z.; Aslam, A.; Ishaq, M.; Gao, W. The edge versions of degree-based topological descriptors of dendrimers, J. Cluster Sci. 2020, 31, 445-452, https://doi.org/10.1007/s10876-019-01658-w.

12. Iqbal, Z.; Ishaq, M.; Aslam, A.; Gao, W. On eccentricity-based topological descriptors of water-soluble dendrimers, Z. Naturforsch. C 2019, 74, 25-33, https://doi.org/10.1515/znc-2018-0123.

13. Kang, S.; Iqbal, Z.; Ishaq, M.; Sarfraz, R.; Aslam, A.; Nazeer, W. On eccentricity-based topological indices and polynomials of phosphorus-containing dendrimers, Symmetry 2018, 10, 237, https://doi.org/10.3390/sym10070237.

14. Kang, S.; Yousaf, M.; Zahid, M.; Younas, M.; Nazeer, W. Zagreb polynomials and redefined Zagreb indices of nanostar dendrimers, Open Phys. 2019, 17, 31-40, https://doi.org/10.1515/phys-2019-0004.

15. Kang, S.; Zahid, M.; Virk, A.; Nazeer, W.; Gao, W. Calculating the degree-based topological indices of dendrimers, Open Chem. 2018, 16, 681-688, https://doi.org/10.1515/chem-2018-0071.

16. Klein, D.J. Topological indices and related descriptors in QSAR and QSPAR, J. Chem. Inf. Comput. Sci. 2002, 42, 1507, https://doi.org/10.1021/ci010441h.

17. Kok, J.; Sudev, N.K.; Mary, U. On chromatic Zagreb indices of certain graphs, Discrete Math. Algorithms Appl. 2017, 9, 1750014, https://doi.org/10.1142/S1793830917500148.

18. Kulli, V. On hyper $\mathrm{kv}$ and square $\mathrm{kv}$ indices and their polynomials of certain families of dendrimers, $J$. Comput. Math. Sci. 2019, 10, 279-286. 
19. Kwun, Y.; Virk, A.; Nazeer, W.; Rehman, M.; Kang, S. On the multiplicative degree-based topological indices of silicon-carbon si2c3-i[p,q] and si2c3-ii[p,q], Symmetry 2018, 10, 320, https://doi.org/10.3390/sym10080320.

20. Li, J.; Zhang, J.; On the second Zagreb eccentricity indices of graphs, Appl. Math. Comput. 2019, 352, 180187, https://doi.org/10.1016/j.amc.2019.01.070.

21. Mehdipour, S.; Alaeiyan, M.; Nejati, A. Computing edge version of eccentric connectivity index of nanostar dendrimers, Kragujevac J..Sci. 2018, 40, 49-56, https://doi.org/10.5937/KgJSci1840049M.

22. Mondal, S.; De, N.; Pal, A. Topological indices of some chemical structures applied for the treatment of covid-19 patients, Polycyclic Aromat. Compd. 2020, https://doi.org/10.1080/10406638.2020.1770306.

23. Mondal, S.; De, N.; Pal, A. Topological properties of graphene using some novel neighborhood degree-based topological indices, Int. J. Math. Ind. 2019, 11, 1950006 https://doi.org/10.1142/S2661335219500060.

24. Qing, X.; Wang, Z.; Munir, M.; Ahmad, H. Molecular irregularity indices of nanostar, fullerene, and polymer dendrimers, J. Chem. 2020, 2020, 9437612, https://doi.org/10.1155/2020/9437612.

25. Sarkar, P.; Pal, A. General Fifth M-Zagreb Polynomials of Benzene Ring Implanted in the P-Type-Surface in 2D Network, Biointerface Res. Appl. Chem. 2020, 10, 6881-6892, https://doi.org/10.33263/BRIAC106.68816892.

26. Veylaki, M.; Nikmehr, M.J.; Tavallaee, H.A. The third and hyper-Zagreb coindices of some graph operations, J. Applied Mathematics and Computing 2016, 50, 315-325, https://doi.org/10.1007/s12190-015-0872-z.

27. Wiener, H. Structural determination of paraffin boiling points, J. Am. Chem. Soc.1947, 69, 17-20, https://doi.org/10.1021/ja01193a005.

28. Xu, K. The Zagreb indices of graphs with a given clique number, Appl. Math. Lett. 2011, 24, 1026-1030, https://doi.org/10.1016/j.aml.2011.01.034.

29. Zheng, J.; Iqbal, Z.; Fahad, A.; Zafar, A.; Aslam, A.; Qureshi, M.I.; Irfan, R. Some eccentricity-based topological indices and polynomials of poly(ethyleneamidoamine) (petaa) dendrimers, Processes 2019, 7, 433, https://doi.org/10.3390/pr7070433. 